\title{
MUSIIKKIKULTTUURIN KOGNITIIVINEN VIITEKEHYS
}

Tiedon antropologia $\bullet$ kognitiiviset kartat $\bullet$ kansan käsitteet $\bullet$ tutkimuslaboratoriot $\bullet$ "autenttiset" tilanteet • "kognitiivinen etnomusikologia" • puhuttu musiikinteoria • luokitusjärjestelmät • kognitio ja musiikin muutos • mentaalinen musiikkikulttuuri • Merriamin malli ja kognitio

Viime aikojen etnomusikologisessa kirjallisuudessa on esiintynyt useita tutkimuksia, jotka sisältävät kognitiivisia kysymyksenasetteluja tai kohdistuvat musiikkikulttuurin tai musiikintekemisen kognitiivisiin aspekteihin. Varsinaisesta "kognitiivisesta etnomusikologiasta" ei kuitenkaan voida kirjoittaa ilman lainausmerkkejä. Kognitiivinen tutkimus ei ilmene etnomusikologiassa vielä erillisenä koulukuntana.

John Blacking on määrittänyt etnomusikologian joissakin suhteissaan osaksi kognitiivista antropologiaa (Blacking 1976: 112). Koska "kognitiivinen etnomusikologia" onkin syntynyt lähinnä antropologiasta saaduista vaikutteista, teen aluksi katsauksen antropologian kognitiivisiin tutkimustapoihin ja tutkimuskohteisiin. Pyrin selkeyttämään kognitiivisen antropologian tutkimustapoja rinnastamalla niitä kognitiivisen psykologian tutkimusmenetelmiin ja päämääriin.

Sen jälkeen esittelen etnomusikologisia tutkimuksia, joissa on mielestäni joko eksplisiittisesti tai implisiittisesti nähtävissä kognitiivisia kysymyksenasetteluja tai tutkimustapoja. Koska "kognitiivinen etnomusikologia" on toistaiseksi suurelta osin perustunut kognitiivisen ant- 
ropologian paradigmalle, ei etnomusikologian piirissä ole vielä keskusteltu tieteenalan omaa kognitiivisen tutkimuksen viitekehyksen kehittämisestä. Kognitiivisesti värittyneiden etnomusikologisten tutkimusten taustalta on kuitenkin selvästi löydettävissä yhteinen näkökulma.

Tässä artikkelissa pyrin eksplikoimaan viitekehyksen, jossa musiikkikulttuuria ja sen osa-alueita voidaan tarkastella kognitiivisesta näkökulmasta. Musiikkikulttuurin kognitiivisen viitekehyksen hahmotuksen pohjaksi olen valinnut etnomusikologian klassikoksi muodostuneen Alan P. Merriamin kolmitasoisen tutkimusmallin.

\section{Kognitiivisen antropologian pääpiirteet}

Käsitteitä kognitio ja kognitiivisuus käytetään tieteellisessä kirjallisuudessa lukuisten eri tieteiden (psykologian, sosiologian, lingvistiikan ja antropologian) alalla viittaamaan monella eri tasolla ja tarkkuudella erilaisiin mentaaleihin ja intellektuaaleihin ilmiöihin ja prosesseihin. Löysimmässä populaarimerkityksessään näiden käsitteiden avulla pyritään tavoittamaan abstrakteja tapahtumia "ihmisen pään sisällä". Kognitiivisuus liittyy ihmisen ajatusmaailmaan, muistiin sekä tiedon vastaan ottamiseen ja käsittelyyn liittyviin prosesseihin. Kognitiolla viitataan myös tietoon, ajatusrakenteisiin sekä ajattelua ohjaaviin sääntöihin ja ajatusreitteihin.

Kognitiivisen antropologian yleisenä pyrkimyksenä on halu ymmärtää ihmisten ajattelumalleja eri kulttuureissa. Ihmisten kulttuurisidonnainen käyttäytyminen järjestyy jaetun symbolisen systeemin perusteella. Kulttuurinen tietous koostuu kategorioista, joiden mukaan ihmiset käsittelevät ja luokittelevat kokemuksiaan. He oppivat kulttuurissaan hyväksyttävän käyttäytymisen säännöt. Sisäistämiensä kognitiivisten karttojen mukaan he tulkitsevat havaitsemaansa käyttäytymistä, tapahtumia ja ilmiöitä. (Spradley 1972: 4.)

Kognitiivisen antropologian tarkoituksena on selittää käyttäytymistä edeltävät ja ohjaavat periaatteet. Kognitiivisen antropologian mukaan kulttuurit eivät koostu materiaalisista ilmiöistä vaan ne ovat materiaalisten ilmiöiden kognitiivisia järjestelmiä. Kognitiivisen antropologian kiinnostuksen kohteena on löytää kullekin kulttuurille olennaiset tekijät ja selittää, miten kansat organisoivat kulttuurinsa merkityksellisiä ilmiöitä. (Tyler 1969: 3.)

Kognitiivisen antropologian juuret ovat strukturaalisessa lingvistiikassa, josta antropologit omaksuivat vaikutteita ja menetelmiä jo 1950-luvun puolivälissä. Samasta lähteestä ovat peräisin monet kognitiivista antropologiaa lähellä olevat antropologian haarat, kuten etnografinen se- 
mantiikka, etnotiede ja uusi etnografia. Itse asiassa rajanveto näiden antropologian osa-alueiden sekä uudemman nk. tiedon antropologian välillä onkin sangen vaikeaa.

Alunperin antropologien kognitioon kohdistuneen kiinnostuksen pohjana oli yksinkertainen oivallus siitä, että ihmiset varmaankin kommunikoivat joillakin tavoilla asioista, jotka ovat heille tärkeimpiä. Ihmisten puheen, diskurssin, ja siinä nimettyjen ilmiöiden kartoittamisen ajatellaan ilmentävän heidän kulttuurista tietouttaan. Tämä lähestymistapa perustuu näkemykseen kielen, ajattelun ja kulttuuri-ilmiöiden keskinäisestä suhteesta, mahdollisesta riippuvuudesta (ks. Sarmela 1984: 34). Tämäntapaisen tutkimuksen tavoitteena on kansan käsitteiden luokitusjärjestelmien ja kieleen pohjautuvien kognitiivisten struktuurien löytäminen.

Kielen merkitystä korostavaa kulttuurisen tietouden tutkimusta on myöhemmin arvosteltu monin tavoin. Kaikki tutkijat eivät välttämättä hyväksy kielen ensiarvoisuutta kulttuurin ilmentäjänä. Kulttuurisidonnaisen tiedon on osoitettu ilmenevän myös muissa kuin lingvistisissä systeemeissä; esimerkiksi ihmiskeho omaa tietoa. Myöhemmässä vaiheessaan kognitiivisesti suuntautunut antropologia onkin laajentunut pelkästä kielen, sen rakenteiden ja kulttuuri-ilmiöiden välisten vastaavuuksien, tutkimuksesta tarkastelemaan myös muita kognitiivisia ilmiöitä, ajatussisältöjä, päätöksenteon prosessia ja päätöksentekoon vaikuttavia tekijöitä sekä kulttuurisidonnaisia sääntöjä.

Kognitiivinen psykologia korostaa kognitiivisten tapahtumien ja ilmiöiden prosessinomaista luonnetta. Kognitiivinen psykologia tutkii individuaalien ajatteluprosesseja, joissa tietoa rakennetaan, käsitellään, siirretään ja vastaanotetaan. Alan tutkimukset käsittelevät myös muistia, ongelmien ratkaisua sekä kieleen liittyviä psykologisia ilmiöitä. (Ks. mm. Hastorf - Isen 1982: 3.) Kognitiivisen psykologian tavoitteena on luoda yleistyksiä yksilöiden ajatteluprosesseista. Psykologian piirissä kognitiivisia prosesseja tutkitaan erilaisissa tehtäväympäristöissä, joissa käyttäytyminen on rajoitettua ja ulkopuoliset ärsykkeet pyritään kontrolloimaan (Laboratory of Human Cognition 1978: 54). Vasta viimeaikaisissa psykologisissa tutkimuksissa on hakeuduttu tutkimuslaboratorioista "kentälle".

Kognitiivisen antropologian menetelmät ja tavoitteet poikkeavat luonnollisesti suuresti perinteisen kognitiivisen psykologian päämääristä. Ensinnäkin tehtäväympäristön antamien ärsykkeiden määrä tuskin koskaan voi olla rajoitettua. Päinvastoin useimmat antropologiset tutkimukset pyrkivät mahdollisimman "autenttisien" tilanteiden tutkimukseen, jossa tutkijan paikallaolon osuus on minimoitu tai, kuten nykyisin yhä useammin, mahdollisimman pitkälle tiedostettu ja analysoitu.

Siinä, missä kognitiivinen psykologia tutkii yksilöiden ajattelupro- 
sesseja, antropologisissa kognitiotutkimuksissa on tieteenalan luonteen mukaisesti useimmiten operoitu yhteisön tai kokonaiskulttuurin tasolla. Tällöin tutkimuksen kohteena ovat pikemminkin olleet kognitiiviset struktuurit, kognitioiden laatu ja sisältö kuin yksilöiden ajatteluprosessit.

Kysymys siitä, onko kognitio tietoista vai tiedostamatonta, on sekä antropologisessa että psykologisessa kirjallisuudessa usein jätetty avoimeksi. On kuitenkin huomattava, että kognitiivisen psykologian piirissä kognitiota on käytetty kuvaamaan myös tiedostamattomia tietämiseen ja vastaanottamiseen liittyviä prosesseja. Siitä, missä määrin kognitiot ovat verbalisoituja, ollaan kuitenkin yksimielisiä: kognitiot koostuvat sekä verbalisoiduista, formuloiduista että mentaaleista elementeistä.

\section{"Kognitiivinen etnomusikologia"}

Musiikin kognitiiviset dimensiot, kognitiot ja kognitiiviset prosessit ovat olleet etnomusikologian tutkimuskohteena jo pitkään. John Blacking on eräs merkittävimpiä musiikin kognitiivisen tutkimuksen puolestapuhujia. Hän pitää musiikkia kognitiivisten prosessien synteesin tuloksena:

Music is a synthesis of cognitive processes which are present in culture and in the human body: the forms it takes, and the effects it has on people, are generated by social experiences of human bodies in different cultural environments (Blacking 1976: 88).

Blackingin mukaan meidän tulisi selvittää, miten musiikin tuottamisen kognitiiviset prosessit toimivat eri kulttuureissa, jotta kykenisimme ymmärtämään ihmisen musikaalisuutta (Blacking 1976: 24 - 25).

Etnomusikologit ovat yrittäneet päästä "ihmisen pään sisälle" tutkimaan musiikkiin liittyvää ajattelua, ajatusrakenteita ja ajattelun sisältöjä monin eri tavoin. Etnomusikologisesta, kognitiivisia musiikkikulttuurin tekijöitä käsittelevästä kirjallisuudesta käy selvästi ilmi etnomusikologian muilta tieteenaloilta lainaava luonne. Kognitiivisen antropologian strukturalistista lingvistiikka lähellä olevat tutkimustavat löytävät vastineensa formalistisissa musiikkikäsitteistöjen luokitusjärjestelmien tutkimuksissa. Musiikkia käsittelevän puheen ja sanaston sisällön tutkimus on oletettavasti saanut alkunsa kognitiivisen antropologian kulttuurin merkityksellisiä tekijöitä etsivästä ja ajattelun sisältöä tutkivasta haarasta. Kognitiivinen psykologia on myös vaikuttanut etnomusikologiaan; tosin musiikin tekemisen kognitiivisten prosessien etnomusikologiset selvitykset ovat toistaiseksi vähäiset. 
Steven Feld on eritellyt lingvististen mallien sovellutusmahdollisuuksia etnomusikologiassa (Feld 1974ab) sekä kielen ja musiikin välisten suhteiden erilaisia tutkimustapoja (Feld 1981). Kognitiivisesti kiinnostava on tutkimustapa, jossa tutkitaan musiikkiin liittyvää kieltä, musiikkisanastoa ja -terminologiaa. Kyseessä ei Fêldin mukaan kuitenkaan ole pelkästään sanalistojen laatiminen vaan "musiikkikielen" tutkiminen "as the metalinguistics denomination of musical concepts in relation to specific societal theories of musical form and performance (Feld 1981: 22)".

Feldin oma kognitiivisen etnomusikologian piiriin luettavissa oleva tutkimus kalulien musiikista menee vieläkin pidemmälle, koska se yhdistää "puhutun musiikinteorian" kulttuurisiin metaforeihin (Feld 1982). Feldin tutkimusta pidetään yhtenä etnomusikologian historian merkkipaaluista (ks. Nattiez 1983: 173).

Musiikkisanastoa musiikkikulttuurin ja musiikkikäyttäytymisen ilmentäjänä ja selittäjänä on tarkasteltu myös muutamissa suomalaisten musiikkikäsitteistöä selvittävissä tutkimuksissa: Philip Donner on tutkinut soittajien musiikinesittämistä koskevaa käsitteistöä sekä soitinrakentamisen käsitteellistämistä (Donner 1976 ja 1983) ja Timo Leisiö kahden erilaisen kulttuuritaustan omaavan henkilön tapaa arvottaa musiikkia (Leisiö 1981). Pirkko Lahtinen on tutkielmassaan selvittänyt käsitteiden avulla kansanlaulajan sävellysprosessia (Lahtinen 1976). Musiikkisanastoa on tutkittu myös kommunikaatioteorioiden näkökulmasta. Musiikkikommunikaatiota kognitiivisena prosessina ovat tutkineet Ruth Stone (1982) ja Carol Robertson (1979).

Strukturalistisesta lingvistiikasta ja lingvistisestä antropologiasta vaikutteita saanut kognitiivinen etnomusikologinen tutkimus kohdistuu myös kielen sisältämiin luokitusjärjestelmiin. Luokitusjärjestelmien tutkimus perustuu siihen oletukseen, että ihmisillä on taipumus kognitiivisesti luokitella asioita ja ihmisiä ryhmiin, tyyppeihin ja muihin luokkiin. Yksinkertaistaakseen monimutkaista todellisuutta ihmiset luonnonmukaisesti järjestävät asioita ja ihmisiä niiden olennaisesti samankaltaisten piirteiden mukaan kognitiivisiksi kategorioiksi. Luokiteltujen "tyyppien" eroista ja samankaltaisuuksista kommunikoidaan sitten yhteisesti sovittujen ja ymmärrettyjen käsitteiden avulla. (Käsitteiden ja käsitejärjestelmien muotoutumisesta ks. Herndon ja McLeod 1981: 137 - 139.)

Musiikkia koskevan diskurssin analysoinnin avulla tutkijat ovat luoneet formaaleja kuvauksia sekä kansan omaamista musiikin luokitus- ja käsitejärjestelmistä (Zemp 1978) että yksilön käsitteiden luokitusjärjestelmistä (Pekkilä 1983).

Ellen Koskoff on tutkinut kognitiivisia rakenteita, joiden avulla yksilöt organisoivat musiikki-informaatiota. Hän päätyy esittelemään musiikki- 
verkosto-metodin (music-network), joka hänen mielestään soveltuu sekä yksilön että ryhmän musiikkiin liittyvien ajattelumallien analyyttiseksi työvälineeksi (Koskoff 1982: 366).

Eräissä etnomusikologisissa tutkimuksissa on pyritty löytämään kulttuurille ominaiset kognitiiviset perusmallit (ks. Wallace 1972). Tällöin tutkimus ei välttämättä kohdistu vain diskurssiin, vaan tarkastelun kohteena voivat olla myös muut kulttuurin aspektit. Näiden tutkimusten a priori -oletus on, että kulttuureilla on tiettyjä kognitiivisia perusrakenteita, jotka ovat kulttuurista käyttäytymistä edeltäviä ja ohjaavia.

Tutkiessaan tiibettiläisille lamoille merkityksellisiä musiikillisia luokkia Ter Ellingson löysi rol-mo -symbaalien soitosta monimutkaisia matemaattisia struktuureita. Hän esittää kysymyksen, missä mielessä nämä matemaattiset struktuurit voivat olla osa tiibettiläistä kognitiivista karttaa (Ellingson 1979: 241). Samat matemaattiset rakenteet hän myöhemmin on löytänyt myös uskonnollisista tansseista, jotka pohjautuvat mandala-kuvioihin. Marcia Herndon on väittänyt, että musiikkiesitykset ovat kulttuurin kognitiivisten aiheiden tiivistelmiä. Tserokeesi-intiaanien musiikkiesityksiä tutkiessaan hän päätyy esittämään, että esitysten kognitiivisesti dualistien rakenne esiintyy kautta linjan tserokeesien kulttuurissa (Herndon 1971: 350 - 351).

Kognitiiviseen etnomusikologiaan voitaneen lukea myös ne tutkimukset, joissa on pyritty kuvaamaan musiikkiin liittyvän ajattelun kognitiivinen sisältö ja sen kautta määrittämään musiikin olennaiset piirteet ja musiikin merkitykset (importances) kulttuurissa. Näitä tutkimuksia on löydettävissä suhteellisen runsaasti. Edward O. Henry on tutkinut pohjoisintialaisessa kylässä asuvien ihmisten tapoja ajatella musiikista sekä sitä, miten musiikin sosiaaliset käyttöyhteydet ja kontekstit liittyvät musiikkia koskeviin perseptioihin, arvoihin, uskomuksiin ja kategorioihin (Henry 1977). Lorraine Sakata on verrannut musiikkiin liittyviä käsitteitä kolmessa afganistanilaisessa kaupungissa (Sakata 1983). Ali Jihed Racy on tutkinut Beirutin muuttuvan ja modernisoituvan ympäristön heijastuksia musiikkia koskevissa verbaalisti ilmaistuissa asenteissa (Racy 1986).

John Blacking on toistuvasti korostanut musiikin kognitiivisten prosessien tutkimisen tärkeyttä. Omassa vendojen initiaatiokoulujen musiikin tonaalista organisaatiota käsittelevässä tutkimuksessaan hän pyrki löytämään yleistyksiä niistä prosesseista, joiden mukaan vendat tekevät musiikkia (Blacking 1970). Blackingin mukaan myös musiikin muuttuminen tapahtuu kognitiivisessa päätöksentekoprosessissa (Blacking 1977). Vaikka Blacking on korostanut prosessien tutkimuksen tärkeyttä, hän joutuu myöntämään, ettei paljoakaan vielä tiedetä ihmisten musiikillisista prosesseista. 
Ulkoeurooppalaista musiikkia on selvitetty musiikkipsykologian menetelmin toistaiseksi perin vähän. Psykologit Jay Dowling ja Done Harwood ovat pyrkineet tutkimaan universaaleja ihmisen kognitiivisia prosesseja, jotka liittyvät musiikin vastaanottamiseen, oppimiseen ja muistamiseen. Alan Lomaxin tutkimuksiin vahvasti nojautuen he tarkastelevat näitä prosesseja myös muutamassa ulkoeurooppalaisessa kulttuurissa ja päätyvät lopulta kuvaamaan musiikillisen käyttäytymisen ja kokemuksen universaaleja piirteitä (Dowling - Harwood 1986: 238 - 239). Balilaisten ja intialaisten musiikin havaitsemisen ja vastaanottamisen kognitiivisia prosesseja on myös tutkittu (Castellano, Bharucha ja Krumhansl 1984 sekä Kessler, Hansen ja Shepard 1984).

Marcia Herndon ja Norma McLeod ovat tutkineet maltalaisten kitaransoittajien ja laulajien musiikkikognitiota musiikinesittämistä koskevien sääntöjen, kognitiivisten karttojen, ajattelustrategioiden ja ajatusreittien avulla (Herndon ja McLeod 1982: 134-170). Musiikin esityssääntöjen tutkimus on hyvin tavallista etnomusikologisissa tutkimuksissa. Sen sijaan musiikin sosiaalisen ja semanttisen tilan kognitiivinen kartoittaminen (mapping) sekä toistuvasti käytettyjen ajatusratojen käyttö musiikkia koskevassa päätöksenteossa ovat toistaiseksi, lukuunottamatta Herndonin ja McLeodin tutkimusta, jääneet lähes tutkimattomaksi alueiksi.

Kuten tämä kirjallisuuskatsaus osoittaa, "kognitiivinen etnomusikologia" näyttää koostuvan perin kirjavasta tutkimusjoukosta. Esitellyt tutkimukset näyttävät kuitenkin jakautuvan neljään ryhmään: 1) Kielen primaarisuuteen pohjaavat tutkimukset, joissa kieltä tutkimalla pyritään selvittämään musiikkiin liittyviä luokitusjärjestelmiä ja musiikkisanastoja 2) Kognitioiden struktuureita ja käyttöstrategioita selvittävät tutkimukset, joissa pyritään selvittämään koko kulttuurin, mukaan lukien musiikin, taustalla olevia kognitioita sekä musiikkiin liittyvässä päätöksenteossa käytettyjä ajatusratoja, karttoja ja sääntöjä 3) Kognition sisältöä kartoittavat tutkimukset, joissa musiikkiin liittyvän puheen ja diskurssin sisältöä analysoimalla pyritään selittämään musiikin ja musiikkikäyttäytymisen merkityksellisiä tekijöitä sekä 4) Musiikkikäyttäytymiseen liittyvien kognitiivisten prosessien tutkimukset, jotka ovat lähellä kognitiivista psykologiaa. On huomattava, että kaikissa tapauksissa ei yhtä tutkimusta voida liittää vain yhteen edellisistä kategorioista, vaan useat kuvatuista tutkimuksista perustuvat useampaan lähestymistapaan. 
Musiikkikulttuurin kognitiivisen tarkastelun pohjaksi sopii kognitiivisen antropologian omaksuma käsitys kulttuurista luonteeltaan sekä mentaalinettä ajatuksen- ja ideankaltaisena. Kognitiivinen kulttuurikäsitys ei sisällä käyttäytymistä vaan rajoittaa kulttuurin käsitteen ajatteluun, uskomuksiin ja tietoon. Nämä kulttuurin mentaalit piirteet ymmärretään käyttäytymistä muotoavana.E. B. Tylorin klassinen määritelmä kulttuurista kompleksina kokonaisuutena, joka kattaa tiedon, uskomukset, taiteen, lait, moraalin, tavat ja kaikki muut käyttäytymismallit sekä sen kapasiteetin, joka vaaditaan yhteisön jäseneltä, korostaa tätä kulttuurin mentaalia ajatustenkaltaista luonnetta (Tylor $1871 \mathrm{I} ; 1$ ).

Ward Goodenoughin kulttuurin määritelmää siteerataan usein kognitiivisen antropologian kirjallisuudessa. Hänen mukaansa kulttuuri "is the forms of things that people have in mind, their models for percieving, relating, and otherwice interpreting them (Goodenough 1957: 167)".

Goodenoughin mukaan yhteisön kulttuuri koostuu kaikesta siitä, mitä henkilön tulee tietää tai mihin hänen tulee uskoa voidakseen toimia muiden jäsenten hyväksymällä tavalla missä tahansa hyväksyttävässä roolissa (ibid.).

Kognitiivisesta kulttuurikäsityksestä johdettuna etnomusikologisessa kognitiivisessa tutkimuksessa musiikkikulttuuri tulisi käsittää ennen kaikkea mentaaliksi ja ajatuksenkaltaiseksi. Tutkimusintressinä ovat tällöin musiikkiin liittyvä ajattelu, uskomukset ja tietous. Kognitiivisen musiikkikulttuurin tutkimuksen kohde voi löytyä mistä tahansa musiikkikulttuurin osa-alueesta; tärkeää on kognitiivinen näkökulma, josta ilmiötä tai asiaa tarkastellaan.

Alan P. Merriamin kolmitasoinen "käsitteet - käyttäytyminen - tuote" tutkimusmalli (Merriam 1964: 32 - 35) tarjoaa mielestäni mielekkään pohjan musiikkikulttuurin kognitiivisen viitekehyksen kehittämiselle. Merriamin mallin tutkimustasojen välisiä painoarvoja säätämällä voidaan selkeyttää musiikkikulttuurin kognitiivisen tutkimuksen edellyttämää näkökulmaa.

Merriamin mallin mukaan musiikkikulttuuri rakentuu musiikkiin liittyvien käsitteiden (concepts) eli musiikin käsitteellistämisen (conceptualization), musiikkiin liittyvän toiminnan eli musiikkikäyttäytymisen (behavior) ja tämän toiminnan tuotteiden (product), myös musiikkiäänen (sound), väliselle dynamiikalle. Palaute, "feedback", tuotteesta käsitteisiin liittää tutkimustasot yhteen siten, että syntyy kuva jatkuvasta vaikutuskierteestä tutkimustasojen välillä.

Merriamin mukaan musiikin käsitteellistäminen koskettelee muun 
muassa kysymyksiä siitä, mitä musiikki on tai mitä sen tulisi olla, mistä musiikki on peräisin ja mitkä ovat inhimillisen musikaalisuuden lähteet (ibid.: 33). Musiikin "käsittämisen" kautta musiikki integroituu yhteisön muihin toimintoihin. Musiikkikäsitykset muodostavat viitekehyksen, jonka mukaan yhteisö organisoi musiikkinsa ja jonka perusteella sen jäsenet ajattelevat, mitä musiikki on ja mitä sen tulisi olla. Merriamin mukaan musiikkiin liittyviä käsityksiä ei välttämättä verbalisoida; niiden tutkimuksen tulisi pohjautua kansan evaluaatioiden analyyttiseen arviointiin. (ibid.: 63.)

Merriamin määrittämä musiikin käsitteellistäminen vastaa pääpiirteiltään etnomusikologisen kirjallisuuden sisäistämää käsitystä musiikkikognitiosta. Niitä ei kuitenkaan pitäisi suoraan rinnastaa toisiinsa kuten eräissä yhteyksissä on tehty (ks. Rice 1987 470). Musiikkikäsitteistö-nimityksen korvaaminen musiikkikognitiolla laajentaa tutkimuksen näkökenttää. $\mathrm{Mu}$ siikkikognition käsite sisältää musiikkikulttuurin kaikki kognitiiviset piirteet. Perinteiset etnomusikologiset musiikkikäsitteistön tutkimukset ovat suuntautuneet musiikkiterminologian ja -sanaston sekä musiikkia koskevien käsitysten ja sääntöjen selvittämiseen. Musiikkikognitio-käsite kattaa lisäksi myös kognitiiviset järjestelmät, struktuurit ja käyttöstrategiat, ajatusreitit ja kognitiiviset kartat. Musiikin käsitteellistämisen tutkimus ei myöskään sisällä mahdollisuutta ymmärtää kulttuurin kognitiiviset struktuurit musiikin syvärakenteiksi. Psykologian tarjoaman tulkintatavan mukaan musiikkikognitio-käsitteeseen sisältyvät myös musiikintekemisen, säveltämisen, esittämisen ja vastaanottamisen kognitiiviset prosessit.

Tutkimusmalliaan esitellessään Merriam kuvaa sen eri tasot toisistaan riippuvaisiksi ja yhdenvertaisiksi: yhtä tasoa (esim. tuotetta) ei voi ilmetä ilman toista (esim. käsityksiä siitä, millainen tuotteen tulisi olla). Mikäli kulttuurin ideankaltainen määrittely otetaan musiikkikulttuurin tutkimisen ja tulkinnan lähtökohdaksi, tulisi Merriamin mallissa musiikin käsitteellistämisen (musiikkikognition) tason merkitystä kuitenkin korostaa. Musiikkikulttuurin kognitiivisessa tulkinnassa musiikkikognition merkitystä painotetaan siten, että se ymmärretään musiikkikäyttäytymistä ja sen tuotteita edeltäväksi ja ohjaavaksi. Merriamin mallin dynaaminen elementti, "feedback" tuotteista musiikkikäsitteisiin, ymmärretään tällöin myös kognitiivisena prosessina.

Merriam on myös korostanut musiikin käsitteellistämisen merkitystä musiikintekemisen prosessissa:

\footnotetext{
"In order to act in a music system, the individual must first conceptualize what kind of behavior will produce the requisite sound (ibid., 33)".
} 
Hänen mukaansa musiikkia koskevat käsitteet ovat sekä musiikillisen äänen että niihin liittyvien asenteiden ja arvojen taustalla (ibid.,103). Myöhemmässä yhteydessä hän selkeästi nostaa esille käsitteiden tutkimuksen ratkaisevan tehtävän musiikintutkimuksessa:

"Concepts about music, then, are basic to the ethnomusicologist who searches for knowledge about a music system, for they underlie the music behavior of all peoples. Without an understanding of concepts, there is no real understanding of music (Merriam 1964: 84)".

Samoin kuin kognitioita ja kognitiivisia ilmiöitä voidaan tutkia niin yksilöprosesseina kuin koko kulttuurille ominaisina järjestelminä myös Merriamin tutkimusmalli soveltuu käytettäväksi sekä yksilön musiikin että musiikkikulttuurin tutkimuksessa. Näin ollen myös kognitiiviseksi viitekehykseksi "hienosäädetty" Merriamin tutkimusmalli soveltuu käytettäväksi sekä musiikkikulttuurin mikro- että makrotasoilla. Ensisijaisesti sosiaalitieteistä lainaavana tieteenä etnomusikologiassa on toistaiseksi esiintynyt vain vähän humanistisille tieteille tyypillisiä yksilötutkimuksia. Yksilöiden käsitejärjestelmien tutkimukset ovat tehneet luonnollisen poikkeuksen tästä suuntauksesta; onhan yksilön käsitejärjestelmä helposti hallittavissa. Viime aikojen etnomusikologiassa on kuitenkin alettu yhä enemmän kiinnostua myös yksilötason tutkimuksista. (Rice 1987: 477 - 481.) Etenkin kognitiivisen psykologian sovellutukset tarjoavat mielenkiintoisia mahdollisuuksia.

Vaikka sekä musiikkikulttuurin mikro- että makrotasojen kognitiiviseen tutkimukseen soveltuu sama tutkimusviitekehys, on näillä tutkimustasoilla luonnollisesti omat ominaislaatunsa, joihin tulisi kiinnittää huomiota. Kulttuurin kognitiivisten ilmiöiden tutkimuksessa tulisi selvittää eri syistä johtuvat variaatiot. Eri ikäryhmien, sukupuolten ja sosiaalisten ryhmien musiikkikognitiot ovat erilaisia. Musiikkiin spesialisoituminen aiheuttaa myös omat kognitiiviset erikoislaatunsa.

Mikrotason yksilötutkimuksissa voidaan päästä selvittämään erityisesti musiikin säveltämisen, oppimisen, esittämisen ja vastaanottamisen kognitiivisia prosesseja. Musiikkiin liittyvien kognitiivisten prosessien tutkimuksessa tulisi eritellä prosessissa läsnäolevina ja vaikuttavina tekijöinä henkilön musiikillinen kompetenssi, "sosiaalinen tietous" musiikista, automaattinen muisti (esim. soittotekniikka, joka ilmenee myös kehon kognitiona) sekä tilannekohtaiset muuttujat. Yksilöiden kognitiivisen musiikkikäyttäytymisen tutkimuksessa tulisi huomioida myös yksilöpsykologiset tekijät. 


\section{Loppusanat}

Kognitiivinen tutkimussuunta on yhteistä monille tieteenaloille. Poikkitieteellisen luonteensa mukaisesti etnomusikologisiin kognitiivisiin tutkimuksiin sisältyy sekä antropologisia, lingvistisiä että psykologisia lähestymistapoja. "Kognitiivisen etnomusikologian" päälähteenä on kuitenkin ollut antropologia ja sen kautta tulleet vaikutteet.

Vaikka "kognitiiviseksi etnomusikologiaksi" luettavissa olevia tutkimuksia on jo merkittävästi ollut esillä etnomusikologian kirjallisuudessa, ei niille vielä toistaiseksi ole tieteenalan piirissä kehitetty yhteistä nimittäjää, viitekehystä. Tässä artikkelissa olen pyrkinyt selkeyttämään kognitiivista tutkimustapaa Alan P. Merriamin klassisen tutkimusmallin pohjalta. Laajentamalla musiikin käsitteellistämisen -tasoa vastaamaan paremmin nykyaikaista musiikkikognition käsitettä ja muuttamalla tutkimusmallin tasojen painotuksia syntyy viitekehys, jonka avulla voidaan kognitiivisesta näkökulmasta tarkastella sekä musiikkikulttuuria yhteisön laajuudella että musiikintekijöiden yksilöprosesseja eli sekä musiikkikulttuurin mikro- että makrotason ilmiöitä.

\section{Lähteet}

Blacking, John

1970 "Tonal Organization in the Music of two Venda Initiation Schools". Ethnomusicology 14:1-56.

1973 How Musical is Man? Seattle: University of Washington Press.

1977 "Some Problems of Theory and Method in the Study of Musical Change". Year book of the International Folk Music Council 9.

1981 "The Problem of "Ethnic" Perceptions in the Semiotics of Music". Steiner, Wendy (toim.), The Sign in Music and Litterature, Austin: University of Texas Press.

Castellano, M.A., Bharucha, J. ja Krumhansl, C.

1984 "Tonal Hierarchies in the Music of North India". Journal of Experimental Psychology 113:394-412

Donner, Philip

1976 "Mitä Juuso Lempinen ajattelee musiikista - Lammilainen viulunsoittaja ja hänen musiikkikäsitteistönsä". Musiikki 1-2:90-117.

1983 "The Frame of Reference of Music - Two Realities". Suomen Antropologi 4/83:184-197.

Dowling, Jay W ja Harwood, Dane L

1986 Music Cognition. Academic Press, Inc. Series in Cognition and Perception. 
Feld, Steven

1974a"Linguistics and Ethnomusicology". Ethnomusicology 18:219-162.

1974b"Linguistic Models and Ethnomusicology". Ethnomusicology 18:197-217.

1981 "'Flow like a Waterfall'": The Metaphors of Kaluli Musical Theory". The Yearbook for Traditional Music 13:22-47.

1982 Sound Sentiment, Birds, Weeping, Poetics and Song in Kaluli Expression. Philadelphia: University of Pennsylvania Press.

Goodenough, Ward

1957 "Cultural Anthropology and Linguistics". Report of the Seventh Annual Roundtable Meeting on Linguistics and Language, toim. Paul Garvin. Washington D.C.: Georgetown University Press.

Hastorf, Albert H. ja Isen, Alice M. (toim.)

1982 Cognitive Social Psychology. New York: Elsevier North-Holland Inc. Henry, Edward O.

1977 "Music in the Thinking of North Indian Villagers". Ethnomusicology 21:1-12.

Herndon, Marcia

1971 "The Cherokee Ballgame Cycle: An Ethnomusicologist's View". Ethnomusicology 15:339-352.

Herndon, Marcia ja McLeod, Norma

1982 Music as Culture. Darby: Norwood Editions.

Kessler, E.J., Hansen, C. ja Shepard, R.N.

1984 "Tonal Schemata in the Perception of Music in Bali and in the West". Music Perception 2:131-165.

Koskoff, Ellen

1982 "The Music-Network: A Model for the Organization of Music Concepts". Ethnomusicology 26:353-370.

Laboratory of Human Cognition

1978 "Cognition as a Residual Category in Anthropology". Annual Review of Anthropology 7:51-71.

Lahtinen, Pirkko

1976 "Laulu on kuin ääneen ajateltu". Musiikki 1976, 1-2: 118-124.

Leisiö, Timo

1983 "Surface and Deep Structure in Music - An Expedition into Finnish Music Cul ture". Suomen Antropologi 4/83:198-208.

Merriam, Alan

1964 The Anthropology of Music. USA: Northwestern University Press.

Nattiez, Jean-Jacques

1983 "Feld, Steven. Sound and Sentiment, Birds, Weeping, Poetics and Song in

Kaluli Expression. A review". Yearbook for Traditional Music 15:173-177.

Pekkilä, Erkki

1983 "'Musiikki' and 'Kappalevalikoima'. Aspects of the Ethno-Theory of a Finnish 
Folk Musician". Suomen Antropologi 4/83:209-217.

Racy, Ali Jihad

1986 "Words and Music in Beirut: A Study of Attitudes". Ethnomusicology 30:413427.

Rice, Timothy

1987 "Toward the Remodelling of Ethnomusicology". Ethnomusicology 31:469-488.

Robertson, Carol E.

1979 "'Pulling the Ancestors': Performance Practice and Praxis in Mapuche Ordering". Ethnomusicology 11:395-416.

Sakata, Hiromi Lorraine

1983 Music in the Mind: The Concepts of Music and Musician in Afghanistan. Kent $\mathrm{OH}$ : Kent University Press.

Sarmela, Matti

1984 Kirjoituksia kulttuuriantropologiasta. Suomen Antropologisen Seuran toimituksia 15. Mikkeli.

Spradley, James P. (toim.)

1972 Culture and Cognition, San Francisco: Chandler Publishing Co.

Stone, Ruth

1982 Let the Inside Be Sweet. The Interpretation of Music Event among the Kpelle of Liberia. Bloomington: Indiana University Press.

Tyler, Stephen (toim.)

1969 Cognitive Anthropology. New York: Holt, Rinehart and Winston.

Tylor, E. B.

1871 Primitive Culture. London: J. Murray.

Wallace, Anthony F.C.

1972 "Culture and Cognition". - Culture and Cognition, toim. Spradley, James P. San Francisco: Chandler Publishing Co. s. 11-128.

Zemp, Hugo

1978 "Are'are Classification of Musical Types and Instruments". Ethnomusicology 23:6-48.

\section{Summary}

The cognitive frame of reference of music culture

The article concentrates of the cognitive study of music with the aim of developing a frame of reference offering a cognitive perspective on music culture and its various areas.

John Blacking's definition of ethnomusicology sees the discipline as part of cognitive anthropology in some of its aspects. At present, cognitive 
studies have not yet emerged as a separate school in ethnomusicology and cognitive approaches are in many cases still on the implicit level in ethnomusicological studies. According to Alan P. Merriam's classic model of research the level of conceptualization of music has directed the interest of many ethnomusicologists towards cognitions related to music.

To a great extent "cognitive ethnomusicology" has thus far been based on the paradigm of cognitive anthropology. The introductory section of the article reviews the main elements of cognitive anthropology and compares its tradition of research with that of cognitive psychology. A review of cognitive studies in ethnomusicology shows that "cognitive ethnomusicology" has been influenced by anthropology, linguistics and psychology. "Cognitive ethnomusicology" appears to include four distinct groups of studies: 1) studies based on the primariness of language, 2) studies investigating the structures and strategies of utilization of cognitions, 3) studies surveying the content of cognition and 4) studies on cognitive processes related to musical behaviour.

A common feature of the above studies is seeing music and related activity from a cognitive perspective. The author has attempted to clarify this perspective on the basis of Alan P. Merriam's model. By expanding the content of the level of conceptualization of music to conform better to the modern concept of musical cognition and by changing the various emphases of the levels of the research model we obtain a frame of reference permitting a cognitive perspective on both music culture on the community level and the individual processes of musicians. In other words, both macro and micro-level phenomena can be approached. The author also discusses the specific nature of these levels and how they should be taken into account in research. 